\title{
Purification and Identification of a Natural Lectin from the Seed of Peanut Arachis hypogaea
}

\author{
Jie Sun, Qing-li Yang*, jie Bi, Chu-shu Zhang, Li-na Yu and Feng Zhu
}

Shandong Peanut Research Institute, Qingdao 266100, China

\begin{abstract}
A natural lectin from the seed of peanut Arachis hypogaea was purified by singlestep affinity chromatography using galactoside-coupled agarose. The native molecular mass of purified A. hypogaea lectin (PN-L) was $29 \mathrm{kDa}$. The lectin PN-L was detected for agglutinating activity, glycoinhibiting action and thermostability. The influence of $\mathrm{pH}$ on those activities was also tested. The results showed that PN-L could not agglutinate three kinds of human erythrocytes. But it showed a strong affinity to human A, B and O erythrocytes (RBC) treated by neuraminidase. Agglutinating activity of PN-L to neuraminidase treated human $\mathrm{O}$ erythrocytes was inhibited by lactose, raffinose, melibiose and D-galactose. The agglutinating activity of peanut seed lectin was stable up to $55^{\circ} \mathrm{C}$ and at $\mathrm{pH} 5.0-11.0$. The results of MALDI-TOFTOF analysis indicated that the protein PN-L showed highly homology with the Peanut Lectin Chain A protein (gi|1942899).
\end{abstract}

Keywords: Peanut, lectin, agglutinating activity, property.

\section{INTRODUCTION}

Lectins are proteins or glycoproteins, usually without catalytic activity, that have the ability to bind to specific carbohydrates expressed on different cell surfaces [1]. They are ubiquitously distributed in nature and most abundant in the Plantae kingdom, where they can be found in seeds, leaves, barks, bulbs, nrhizomes, roots and tubers depending on the plant species [2-6]. However, the majority of the studies on lectins have been carried out on legume species $[7,8]$ particularly in their seeds where they comprise up to $15 \%$ of the total protein. They have attracted great interest because of their various biological activities, such as cell agglutination, antiproliferative, antitumor, immunomodulatory, antifungal, and antiviral [9-14]. They have emerged as an important class of proteins having a wide variety of biochemical applications including their use in bioseparation [15] and reversible immobilization [16].

Seeds of legumes such as peas and beans have long been known to represent a rich source of lectins [17]. Legume lectins are the best-studied group of lectins and hundreds of these proteins have been isolated and extensively investigated in relation to their chemical, physicochemical, structural, and biological properties. The present investigation has been devoted to purify and characterize a D-galactose-binding lectin from seeds of peanut. The lectin has been studied with respect to its structure, composition, biological activity, and sugarspecificity. These properties were compared to other reports on legumes lectins.

*Address correspondence to this author at the Shandong Peanut Research Institute, Fushan Road No. 126, Licang District, Qingdao 266100, China; Tel: +86-532-87611087; Fax: +86-532-87611087;

E-mail: rice407@sohu.com,rice407@163.com

\section{MATERIALS AND METHODS}

\subsection{Materials and Reagents}

Dried peanut were used for all the experiments in this study. The fruits were collected in 2009 during the September season at the farm of Laixi in China. Neuraminidase N2876 and galactoside-agarose were purchased from Sigma Chemical Company, USA. Typed human blood cells (A, B, and O) were obtained from healthy donors. All other reagents were either of analytical grade or of the highest quality available.

\subsection{Extraction of and Purification Lectin}

Peanut seed $(5.0 \mathrm{~g})$ was broken into pieces (approx $1 \mathrm{~mm})$, added to a 10 -fold volume $(50 \mathrm{ml})$ of $50 \mathrm{mM}$ phosphate buffer ( $\mathrm{pH}$ 7.2) and extracted at $4{ }^{\circ} \mathrm{C}$ for $16 \mathrm{~h}$. Supernatant obtained by centrifugation $(10,000 \mathrm{~g}$ for $20 \mathrm{~min})$ was then used for lectin purification. Proteins in the supernatant were fractionated by ammonium sulfate precipitation $(20-60 \%$ saturation). The precipitate was resuspended and dialyzed extensively against $50 \mathrm{mM}$ phosphate buffer (PBS pH 7.2) before applied to affinity chromatography on a galactoside-agarose column $(10 \times 1.5$ $\mathrm{cm})$ pre-equilibrated and eluted with the same buffer. unbound material was washed from the column with a PBNaIbuffer $(35 \mathrm{mM} \mathrm{NaCl} 50 \mathrm{mM}$ PBS, pH 7.2), until the O.D.280 of eluents was below 0.01. Subsequently, the column was washed with a PB-Nallsalt buffer $(500 \mathrm{mM} \mathrm{NaCl}$ $50 \mathrm{mM}$ PBS, pH 7.2) until the O.D.280 of eluents was below 0.01 and then re-equilibrated with $50 \mathrm{mM}$ PBS at a 0.2 $\mathrm{ml} / \mathrm{min}$ flow rate. The lectin was desorbed with with $0.2 \mathrm{M}$ D-Lactose in $50 \mathrm{mM}$ PBS at a $0.5 \mathrm{ml} / \mathrm{min}$ flow rate. The fractions, which showed absorbance at $280 \mathrm{~nm}$, were collected and dialyzed extensively against $50 \mathrm{mM}$ PBS at $4{ }^{\circ} \mathrm{C}$ 
overnight to remove D-Lactose. The fractions containing haemagglutinating (HA) activity were pooled, lyophilized and stored at $-70^{\circ} \mathrm{C}$ for further analysis. The effluent $(4.5 \mathrm{ml}$ fractions) collected after adsorption, washing, and elution was assayed for hemagglutinating activity (HA) [18].

\subsection{Preparation of RBC Suspension}

For human red blood cells (RBC)preparation, the extracted $\mathrm{RBC}$ were centrifuged at $500 \mathrm{~g}$ for $5 \mathrm{~min}$, and then washed with PBS three times, and diluted to a $2 \% \mathrm{RBC}$ suspension. The diluted RBC suspension (in PBS, $10 \mathrm{ml}$ ) was treated with $1 \mathrm{ml}$ neuraminidase $(100 \mu \mathrm{g} / \mathrm{ml})$ for $1 \mathrm{~h}$ at $37^{\circ} \mathrm{C}$. Then the cells were washed by buffer PBS three times [19].

\subsection{Hemagglutination Assays}

Hemagglutination assays (HA) were performed in Vbottom microtiter plates according to the method described by Murali S et al. [20]. The HA titers were recorded as the reciprocal of the highest dilution of the sample causing complete agglutination of RBC. Contol was substituted the sample by $50 \mathrm{mM}$ PBS, $\mathrm{pH} 7.2$. The HA assay was repeated three times.

\subsection{Hemagglutination-Inhibition Assays}

The specificity of the HA-inhibition activity was investigated by using a variety of carbohydrates. The potential inhibitors were serially diluted with $50 \mathrm{mM}$ PBS, pH 7.2 (carbohydrates, $0.2 \mathrm{M}$ ), and then incubated with an equal volume of the PN-L (4 hemagglutination units or 4 $\mathrm{HU}$, final concentration) for $30 \mathrm{~min}$ at $\mathrm{RT}$, prior to the agglutination assays. The inhibitory capacity was expressed as the minimum concentration of the tested substance that completely inhibited $4 \mathrm{HU}$. The HA-inhibition assays were repeated three times.

\subsection{Electrophoresis}

The purity of the lectin during the purification steps was tested by SDS-PAGE according to the procedure of Laemmli [21], using $12 \%$ total concentration polyacrylamide as the separating gel and 4\% polyacryl-amide as the stacking gel. The molecular weight of PN-L was determined by SDSPAGE under reducing and non-reducing conditions. The separated proteins were stained with Comassie Brilliant Blue $\mathrm{R}-250$. The protein concentration of the different samples was determined through the method of Bradford, using BSA (bovine serum albumin) as standard.

\subsection{Effect of $\mathrm{pH}$ and Temperature on Hemagglutinating Activity}

The effect of $\mathrm{pH}$ on the hemagglutinating activity of purified lectin was carried out by preincubating the samples with buffers of different $\mathrm{pH}$ : $0.05 \mathrm{M}$ sodium acetate/acetic acid ( $\mathrm{pH} 4-5), 0.05 \mathrm{M}$ sodium phosphate $/ \mathrm{HCl}$ ( $\mathrm{pH}$ 6-7), 0.05 $\mathrm{M}$ Tris/ $\mathrm{HCl}(\mathrm{pH} 8-9)$ and $0.05 \mathrm{M}$ glycine/NaOH $(\mathrm{pH} 9-11)$ for $12 \mathrm{~h}$ at $4^{\circ} \mathrm{C}$. The solution was subsequently incubated with $50 \mathrm{mM}$ PBS at room temperature then neutralized to $\mathrm{pH}$ 7.2. The agglutinating activity of samples was checked using a $2 \%$ suspension neuraminidase treated human O RBC.

The effect of temperature on the hemagglutinating activity of purified lectin was examined after the lectin was incubated in PBS for $10 \mathrm{~min}$ at various temperatures $(25,30$, $\left.40,50,55,60,65,70,75^{\circ} \mathrm{C}\right)$. The residual agglutinating activity of the lectin was checked as described previously.

\subsection{Effect of EDTA and $\mathrm{Ca}^{2+}$ on Hemagglutinating Activity}

To investigate the role of $\mathrm{Ca}^{2+}$ ions on hemagglutination, the lectin was stripped of $\mathrm{Ca}^{2+}$ ions by adding $50 \mu \mathrm{l}$ of $25 \mathrm{mM}$ EDTA to $50 \mu \mathrm{l}$ of the lectin $(63.84 \mu \mathrm{g} / \mathrm{ml})$. The extent of hemagglutination was determined after $30 \mathrm{~min}$ incubation at room temperature.

\subsection{MALDI-TOF-TOF MS of the Lectin}

The MALDI-TOF MS and MALDI-TOF-TOF MS analysis of PN-L were determined by $4700 \mathrm{MS} / \mathrm{MS}$ spectrometry in Beijing Proteome Research Center.

\section{RESULTS}

\subsection{Purification of Lectin}

Purification of the lectin PN-L from the seed of peanut $A$. hypogaea was achieved by one chromatographic steps, with a galactoside-agarose column. The unretained fraction was eluted with a PB-NaIbuffer and a PB-Na II buffer. The elution had no hemagglutinating activity in the presence of tested erythrocytes. The lectin eluted with $0.2 \mathrm{M}$ D-Lactose in $50 \mathrm{mM}$ PBS showed hemagglutinating activity. Lectin crude extraction was applied to the column and on elution with lactose in PBS yielded $63.83 \mu \mathrm{g}$ of pure lectin. The specific activity of lectin was increased by 4032-fold compared to that of the crude extraction. Analysis of purified lectin on SDS-PAGE in the absence of Dithiothreitol (DTT) revealed a single band at $29 \mathrm{kDa}$. However, upon reduction with DTT this lectin was still a single protein bands whose molecular weights was $29 \mathrm{kDa}$ (Fig. 1).

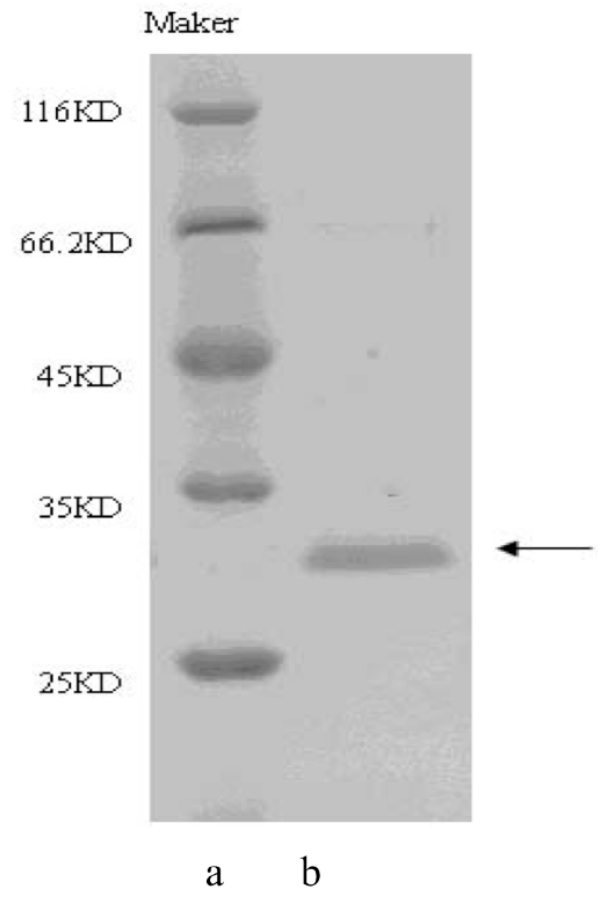

Fig. (1). Electrophoretic analysis of PN-L from A.hypogaea. SDS-PAGE of FC-L from Fetuin-agarose affinity chromatography $(12 \%)$ lane a: Marker, lane b: PN-L. 


\subsection{Hemagglutination Assays and Hemagglutination- Inhibition Assays}

PN-L didn't have the capacity to agglutinate three types of the human A, B, O erythrocytes. But it could intensively agglutinat the $\mathrm{RBC}$ which treated by neuraminidase. The HA activity of PN-L against different erythrocytes is given in Table 1. The strongest agglutination titer was towards treated human $\mathrm{O}$ erythrocytes. Neuraminidase-treated erythrocytes were more agglutinated than the untreated ones, suggesting a preferential affinity of the activity towards nonsialoglycoconjugates.

Table1. Hemagglutinating Activity of Purified PN-L

\begin{tabular}{|c|c|}
\hline \multirow{3}{*}{ Type of Erythrocytes } & Hemagglutinating Titer \\
\cline { 2 - 2 } & Untreated Neuraminidase Treated \\
\hline \hline Human A & $02^{10 \pm 0.58}$ \\
Human B & $02^{10 \pm 0.58}$ \\
Human O & $02^{11 \pm 1.00}$ \\
\hline
\end{tabular}

The sugar specificity of purified lectin PN-L was investigated by competitive inhibition of various carbohydrates and glycoproteins. Of the 11 carbohydrates tested, only 4 kinds of sugars had binding specificity. None of the three N-acetyl sugars namely, N-Acetylneuraminic acid (NeuAc), N-acetylglucosamine (GlcNAc) and Nacetylgalactosamine (GalNAc) inhibited the agglutinating activity of PN-L (Table 2). In contrast, some monosaccharides or oligosaccharides namely, D-Galactose, Lactose, D-Raffinose, Melibiose inhibited the HA activity of PN-L even at very low concentrations (1.56. or $6.25 \mathrm{mM}$ ).

\subsection{Effect of $\mathrm{pH}$ and Temperature}

The optimum $\mathrm{pH}$ for purified PN-L to agglutinate human $\mathrm{O}$ erythrocytes was5.0-8.0. Its capacity was reduced below pH 5.0 and above $\mathrm{pH}$ 9.0. The HA activity of the lectin was inhibited at $\mathrm{pH}<5.0$. HA activity was observed between $\mathrm{pH}$ 5.0-11.0 (Table 3). Purified PN-L retained the full agglutinating activity over the temperature range of $0-40{ }^{\circ} \mathrm{C}$, but there was a dramatic decrease between 50 and $55^{\circ} \mathrm{C}$, and at $55^{\circ} \mathrm{C}$ the activity was completely abolished (Table 4).

\subsection{Requirement of Divalent Calcium}

The activity of this lectin is dependent on the availability of $\mathrm{Ca}^{2+}$. Treatment of purified PN-L with $20 \mathrm{mM}$ EDTA, the agglutination activity was partly inhibited. Furthermore, the activity was completely restored when $\mathrm{Ca}^{2+}$ was added into the reaction system.

\subsection{MALDI-TOF-TOF MS of the Lectin}

Fig. (2) showed the result of MALDI-TOF analysis of PN-L. Fig. (3) showed the result of MALDI-TOF-TOF analysis of PN-L. These database search results indicated that the protein PN-L showed highly homology with the Peanut Lectin Chain A protein (gi|1942899). The fitting degree of these two protein was $81 \%$. This result suggested that PN-L and gi|1942899 are same protein in the peanut seed.

Table 2. Agglutinating Activity of Purified PN-L Against Various Carbohydrates

\begin{tabular}{|c|c|c|}
\hline Carbohydrates Tested & Maximum Concentration Tested & Minimum Inhibitory Concentration \\
\hline \hline Lactose & $200 \mathrm{mM}$ & $1.56 \mathrm{mM}$ \\
D-Galactose & $200 \mathrm{mM}$ & $6.25 \mathrm{mM}$ \\
L-Rhamnose & $200 \mathrm{mM}$ & - \\
D-Xylose & $200 \mathrm{mM}$ & - \\
D-Raffinose & $200 \mathrm{mM}$ & - \\
Sucrose & $200 \mathrm{mM}$ & - \\
D-Fructose & $200 \mathrm{mM}$ & $12.5 \mathrm{mM}$ \\
Melibiose & $200 \mathrm{mM}$ & - \\
N-Acetylglucosamine (GlcNAc) & $200 \mathrm{mM}$ & - \\
N-Acetylgalactosamine (GalNAc) & $200 \mathrm{mM}$ & - \\
N-Acetylneuraminic acid (NeuAC) & $200 \mathrm{mM}$ & \\
\hline
\end{tabular}

Note: "-": no agglutinating activity at the concentration of $200 \mathrm{mmM}$.

Table 3. Effect of pH on the Agglutination of Erythrocytes by PN-L

\begin{tabular}{|c|c|c|c|c|c|c|c|c|c|c|}
\hline $\mathbf{p H}$ & 4 & 5 & 6 & 7 & 8 & 9 & 10 & 11 & 12 & Control \\
\hline Hemagglutinating activity & 0 & $2^{5 \pm 0.00}$ & $2^{5 \pm 0.00}$ & $2^{4 \pm 0.00}$ & $2^{4 \pm 0.00}$ & $2^{3 \pm 0.00}$ & $2^{3 \pm 0.00}$ & $2^{3 \pm 1.00}$ & 0 & $2^{5 \pm 0.00}$ \\
\hline
\end{tabular}

Table 4. Effect of Temperature on the Agglutination of Erythrocytes by PN-L

\begin{tabular}{|c|c|c|c|c|c|c|c|c|}
\hline Temperature & $\mathbf{2 5}$ & $\mathbf{3 0}$ & $\mathbf{4 0}$ & $\mathbf{5 0}$ & $\mathbf{5 5}$ & $\mathbf{6 0}$ & $\mathbf{6 5}$ & $\mathbf{C o n t r o l}$ \\
\hline \hline Hemagglutinating activity & $2^{5 \pm 0.00}$ & $2^{4+0.00}$ & $2^{4 \pm 0.00}$ & $2^{3 \pm 0.00}$ & 0 & 0 & 0 & $2^{5 \pm 0.00}$ \\
\hline
\end{tabular}




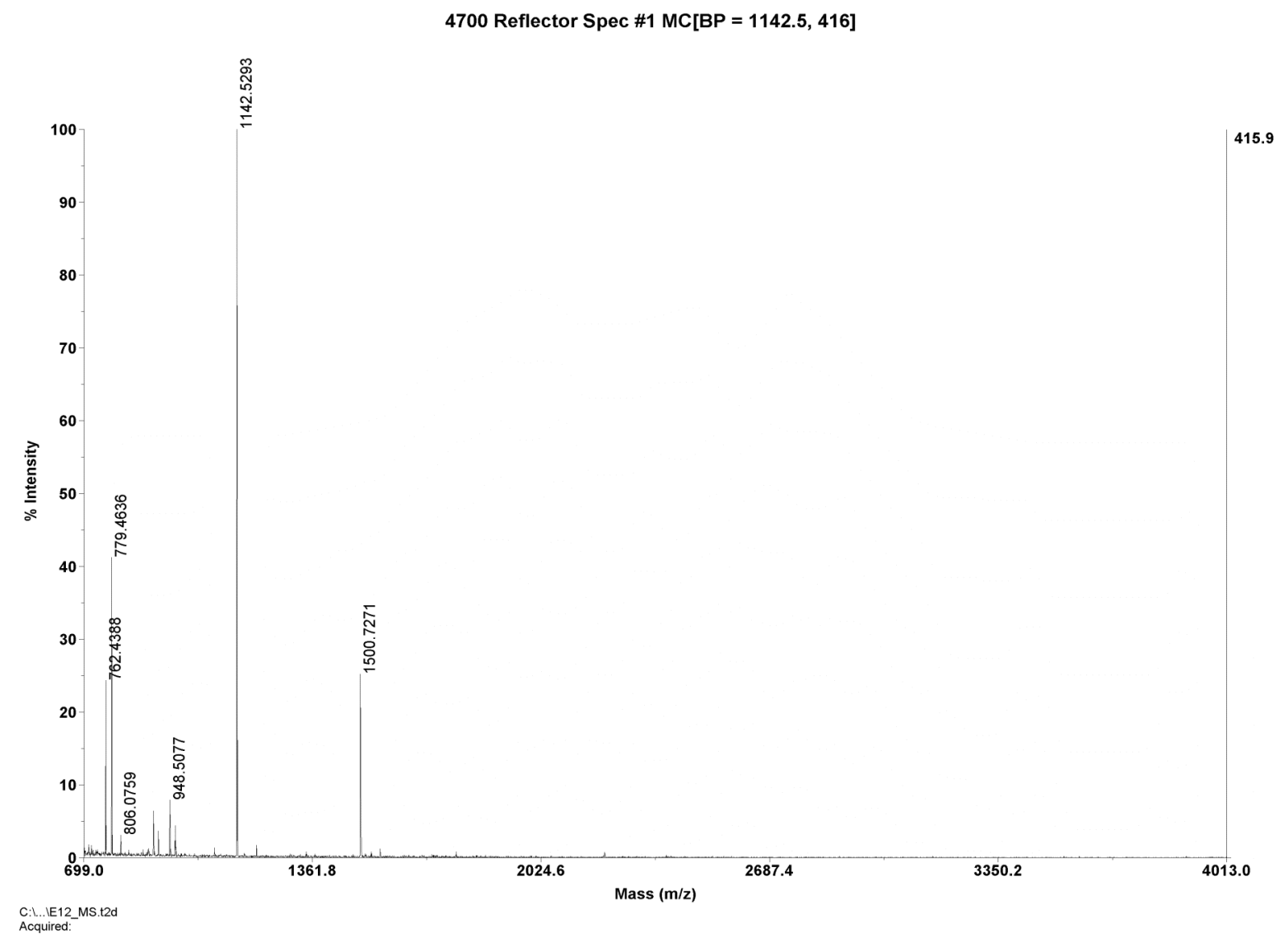

Fig. (2). MALDI-TOF analysis of PN-L from A.hypogaea.

$4700 \mathrm{MS} / \mathrm{MS}$ Precursor 1142.53 Spec \#1 MC[BP = 120.1, 236]

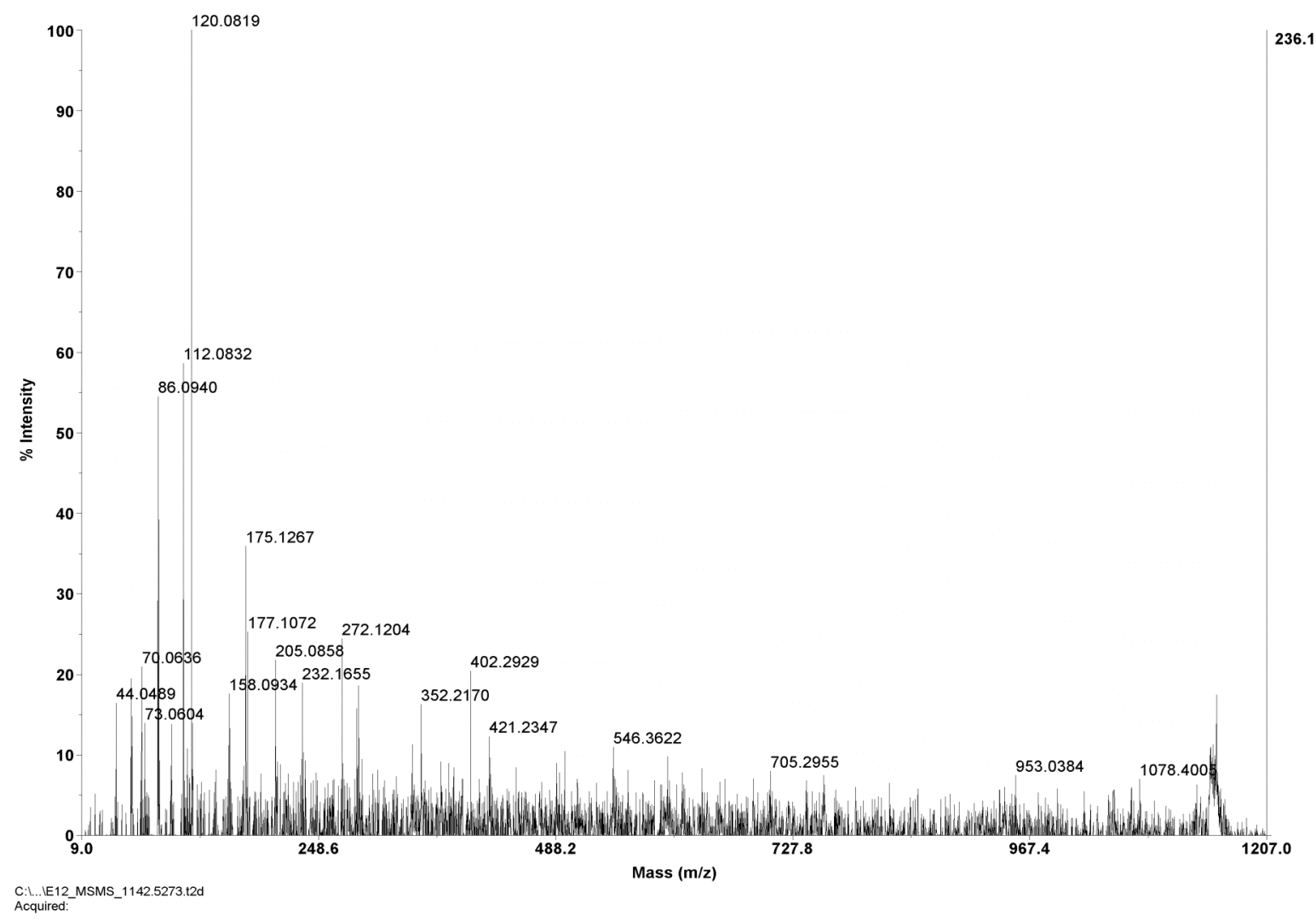

Fig. (3). MALDI-TOF- TOF analysis of PN-L from A.hypogaea. 


\section{DISCUSSION}

The presence of naturally occurring lectins in the haemolymph of several plants has been well known since the beginning of the $20^{\text {th }}$ century. Most current research has emphasized the biochemical applications of lectins, such as antitumor, immunomodulatory, antifungal, antiviral. and so on [10-13]. In the present study, a new lectin PN-L was purified from the seed of peanut A. hypogaea by affinity chromatography. SDS-PAGE analysis revealed one band with a molecular mass of $29 \mathrm{kDa}$. This agglutinin appeared to be a C-type agglutinin, as $\mathrm{Ca}^{2+}$ is required for it's HA activity [22] and it was reversibly sensitive to EDTA. The lectin specific activity was increased 4032-fold following purification. PN-L didn't have the capacity to agglutinate three types of human erythrocytes and it could not discriminate human A, B and O RBC types. While Neu5Ac is the major type of the sialic acid found in human erythrocytes, which account for $30 \%$ of the total sialic acid respectively [23,24]. PN-L could not to combine NeuAc (Table 2) on the surface of erythrocytes. However, after treated by neuraminidase which removed the NeuAc on the surface of the erythrocytes, PN-L could agglutinate these three types of human erythrocytes. Its agglutination activity is similar to the lectin found in jacalin.

The inhibitory analysis showed that $\mathrm{N}$-acetylated sugars and sialylated glycoproteins had no inhibition on PN-L agglutinating activity. Among the carbohydrates tested, the following sugars had inhibition at $200 \mathrm{mM}$ : D-Galactose, Lactose, D-Raffinose, Melibiose. They were effective inhibitors of haemagglutination. Lactose was the strongest inhibiter, which inhibited the HA activity of PN-L at a concentration of $1.56 \mathrm{mM}$. These were similar with another peanut lectin PNA and Dolichos biflorus agglutinin (DBA), which could distinguish servel cancer cell [25]. Thses result drop a hint that PN-L might a potential distinguish factor on cancer diagnosis. The fitting degree of PN-L and Lectin Chain A protein (gi|1942899) was $81 \%$. These results confirmed that the protein we purified was the translateed protein of Peanut Lectin Chain A protein.

In conclusion, a putative lectin PN-L was successfully purified from peanut $A$. hypogaea. PN-L was able to recognize the terminal $\mathrm{D}$-Galactose and Lactose groups in the oligosaccharide chain of glycoconjugates. Further investigation is required to focus on the biochemical characters and precise applications on cancer diagnosis.

\section{REFERENCES}

[1] Marques MRF, Barracco MA. Lectins, as non-self-recognition factors, in crustaceans. Aquaculture 2000; 191: 23-44.

[2] Diaz CL, Hosselet M, Logman GJJ, Van Driessche E, Lugtenberg BJJ, Kijne JW, Distribution of glucose/mannosespecific isolectins in pea (Pisum sativum L.) seedlings. Planta 1990; 181: 451-461.

[3] Hankins CN, Kindinger JI, Shannon LM, The lectins of Sophora japonica. Purification, properties, and N-terminal amino acid sequences of 5 lectins from bark. Plant Physiol 1988; 86: 67-70.
[4] Van Damme EJM, Astoul CH, Barre A, Rouge P, Peumans WJ. Cloning and characterization of a monocot mannosebinding lectin from Crocus vernus (family Iridaceae). Eur J Biochem 2000; 267: 5067-77.

[5] Wright LM, Van Damme EJM, Barre A, et al. Isolation, characterization, molecular cloning and molecular modelling of two lectins of different specificities from bluebell (Scilla campanulata) bulbs. Biochem J 1999; 340: 299-308.

[6] Zhu K, Huesing JE, Shade RE, et al. An insecticidal Nacetylglucosamine-specific lectin gene from Griffonia simplicifolia (Leguminosae). Plant Physiol 1996; 110: 195-202.

[7] Kocourek J, Historical Background. In Liner IE, Sharon N, Goldstein IJ, Eds. The Lectin: Properties, Functions, and Application in Biology and Medicine. Academic Press Inc., New York, 1986; pp. 1-32.

[8] Lakhtin VM. Molecular organization of lectins (a review). Mol Biol 1994; 28: 157-77.

[9] Broekaert WF, Van Parijs J, Leyns F, Joos H, Peumans WJ. A chitinbinding lectin from stinging nettle rhizomes with antifungal properties. Science 1989; 245: 1100-2.

[10] Wang HX, Liu WK, Ng TB, Ooi VEC, Chang ST. The immunomodulatory and antitumor activities of lectins from the mushroom Tricholoma mongolicum. Immunopharmacology 1996; 31: 205-11.

[11] Does MP, Houterman PM, Dekker HL, Cornelissen DJC. Processing, targeting and antifungal activity of stinging nettle agglutinin in transgenic tobacco. Plant Physiol 1999; 120: 421-31.

[12] Ye XY, Ng TB, Tsang PWK, Wang J. Isolation of a homodimeric lectin with antifungal and antiviral activities from red kidney bean (Phaseolus Vulgaris) seeds. Protein Chem 2001; 20: 367-75.

[13] Wong JH, Ng TB. Purification of a trypsin-stable lectin with antiproliferative and HIV-1 reverse transcriptase inhibitory activity. Biochem Biophys Res Commun 2003; 301: 545-50.

[14] Singh J, Singh J, Kamboj SS. A novel mitogenic and antiproliferative lectin from a wild cobra lily, Arisaema favum. Biochem Biophys Res Commun 2004; 318: 1057-65.

[15] Goldstein IJ, Poretz RD. The Lectins - Properties, Functions and Applications in Biology and Medicine. Orlando: Academic Press, 1986; 8: $33-243$

[16] Cabral JMS, Kennedy JF. Immobilization techniques for altering thermal stability of enzymes. In: Gupta MN, Ed. Thermostability of Enzymes. Gerrnany/Narosa, India, Springer-Verlag, 1993; pp. 162- 7.

[17] Kalsi G, Das HR, Babu CR, Das RH. Isolation and characterization of a lectin from peanut roots, Biochim Biophys Acta 1992; 1117: 114-9.

[18] Sun J, Wang L, Wang BJ, et al. Purification and characterization of a natural lectin from the plasma of the shrimp Fenneropenaeus chinensis. Fish Shellfish Immunol 2008; 25: 290-7.

[19] Belogortseva NI, Molchanova VI, Kurika AV, et al. Isolation and characterization of new GalNAc/Gal specific lectin from the sea mussel Crenomytitlus grayanus. Comp Biochem Physiol 1998; 119: 45-50.

[20] Murali S, Mullainadhan P, Arumugam M. Purification and characterization of a natural agglutinin from the hermit crab Diogenes affinis. Biochim Biophys Acta 1999; 1472: 13-24.

[21] Laemmli UK. Cleavage of structural proteins during the assembly of the head of bacteriophage T4. Nature 1970; 227: 680-685.

[22] Drickamer K. $\mathrm{Ca}^{2+}$ dependent carbohydrate-recognition domains in animal proteins. Curr Opin Struct Biol 1993; 3: 393-400.

[23] Schauer R, Casalsst J, Corfield AP, et al. Subcellular site of the biosynthesis of O-acetylated sialic acids in bovine submandibular gland. Glycoconjug 1988; 5: 257-70.

[24] Herrler G, Reuter G, Rott R, et al. N-acetyl-9-O-acetylneuraminic acid, the receptor determinant for influenza Cvirus, is a differentiation marker on chicken erythrocytes. Biol Chem Hoppe Seyler 1987; 368: 451-4.

[25] Petrossian K, Banner LR, Oppenheime SB. Oppenheime. Lectin binding and effects in culture on human cancer and non-cancer cell lines: examination of issues of interest in drug design strategies. Acta Histochem 2007; 109: 491-500. 